\title{
Exploration and Analysis of the New Paradigm of Human Resources Management in the Digital Age
}

\author{
Xiaoyi Liu*, Zhongxian Fu \\ School of Finance and Economics Management, Sichuan University of Arts and Science, Dazhou, China \\ Email: *lxy_423@163.com
}

How to cite this paper: Liu, X.Y. and Fu, Z.X. (2019) Exploration and Analysis of the New Paradigm of Human Resources Management in the Digital Age. Open Access Library Journal, 6: e5863.

https://doi.org/10.4236/oalib.1105863

Received: October 17, 2019

Accepted: November 4, 2019

Published: November 7, 2019

Copyright $\odot 2019$ by author(s) and Open Access Library Inc.

This work is licensed under the Creative Commons Attribution International License (CC BY 4.0).

http://creativecommons.org/licenses/by/4.0/

\begin{abstract}
The digital age has profoundly changed the mode of social production and human's life style. New technologies represented by Internet, Internet of Things, big data, cloud computing and artificial intelligence are deeply integrated with real economy and virtual economy to promote the paradigm of human resources management and enterprise management mode to transform towards digitalization. How to comprehensively improve the digitalized viability of enterprises has become an important issue to be studied and solved urgently. This paper expounds the development trend of the new paradigm of human resources management in the digital age, analyses the opportunities and challenges faced by human resources management in the digital age, and discusses about the specific strategies for constructing the new paradigm of human resources management in the digital age, such as precise selection of personnel, construction of the information interaction platform and data mining. We should construct the interest appeal platform, know how to judge people and use them, establish the talent sharing platform with cross-border thinking, establish the value creation platform, and allow the construction of platforms to help the new paradigm of human resources management to better serve enterprises, thus creating more economic benefits for enterprises.
\end{abstract}

\section{Subject Areas \\ Human Resource Management}

\section{Keywords}

Digital Age, Human Resources Management, New Paradigm 


\section{Introduction}

With the advent of the $21^{\text {st }}$ century, and gradual rise and constant self-breakthrough of information technology and network technology, new media has been created. The advent of new media has also brought us a new age-the information age, also known as the digital age. In the digital age, talents have become the most important strategic resource of enterprises and an important factor in promoting the development of enterprises. Under this background, human resources management of enterprises has become very important. However, traditional human resources management is mainly based on labor management. Today, with the continuous development of information technology, information technology has been used in the management of some links, such as recruitment, hiring, training of new employees and performance assessment of enterprises, but there is still a long way to go from the construction of the digital platform of human resources management. It is the repair of the traditional paradigm, rather than a new paradigm of human resources management in the digital age, which is far from the actual development needs of human resources management. Through the research on the new paradigm of human resource management in the digital era, we can find that there are a lot of shortcomings and loopholes in traditional human resource management. For example, human resource staff are still needed to complete some heavy routine tasks in traditional human resources, which will not only reduce work efficiency, but also increase the fault tolerance rate of work and affect organizational performance. With the continuous development of digital economy, there are many modern information technologies, which can make up for the shortcomings of traditional human resource management, greatly improve the efficiency of human resource management, improve the comprehensiveness and accuracy of human resource management, and then bring more economic benefits for enterprises, and promote the realization of organizational goals.

\section{Digital Age Calls for Innovation of Human Resources Management Paradigm}

\subsection{Digital Age}

The digital age [1] is a form of communication that provides information and entertainment services to users through Internet, broadband LAN, wireless communication network, satellite and other channels, as well as terminals such as computers, mobile phones and digital television, with digital technology and network technology. It is also a term of the age of electronic information. Because all machine languages of electronic information are represented by the combination of number 0 and 1 , people call it the digital age. In this age, lowcost, barrier-free and zero-distance interactive communication between people will produce a large amount of data, which implies the information and knowledge generated by people's needs, personality characteristics, emotional changes and in-depth communication. Business decision-making of enterprises will increa- 
singly rely on the knowledge behind data. Data will enable the accumulation, application, transformation and innovation of knowledge in enterprises faster, more direct and more effective, so that human beings can truly enter the digital economy age.

\subsection{Human Resources Management Paradigm}

\subsubsection{Management Paradigm}

The so-called "paradigm" mentioned by Peter Drucker [2] in his book Discussion about the Challenges of Management in the $21^{\text {st }}$ Century refer to the "basic assumptions of reality" of social sciences such as management. "They are usually something held subconsciously by scholars, narrators, teachers and practitioners in the field of disciplines and included in disciplines by various expressions." As a result, they "determine the reality of discipline assumptions to a large extent". They determine the "facts" identified by disciplines. "In fact, a discipline identifies everything of it", and also determines the "neglected or ignored part due to regarding as a trouble and accident" "to a large extent". Thus, "paradigm" is important.

\subsubsection{Old Paradigm of Human Resources Management}

The human resources management with old paradigm is defined as follows. Based on the established strategic objectives, an enterprise achieves the goal of improving the overall labor productivity on the basis of analyzing work, planning resources, employing staffs, evaluating staff performance, making salary management, encouraging enterprise members, training enterprise personnel, etc., in order to achieve the established goal of making profits of the enterprise. To do a good job in human resources management, it must first design the corresponding strategies and plans, make a full analysis based on the reasonable guidance of the plans, and establish job descriptions and introductions. Then, according to the specific requirements of job analysis, it should select and employ talents needed by the enterprise, and make reasonable arrangements and utilization. In this link, it must make reasonable planning of the staffs' horizontal and vertical development channels, and ensure that the enterprise and talents promote each other and develop together in the process of continuous matching, while effectively and rationally resolving differences and contradictions between the enterprise and personnel, making adequate exchanges, coming into contact with the communication barriers, and ensuring smooth completion of related work.

\section{Opportunities and Challenges of Human Resources Management in the Digital Age}

\subsection{Opportunities of Human Resources Management in the Digital Age}

At present, driven by the development of information technology, human society has entered the digital age, and all walks of life have undergone tremendous 
changes. Information technology is an effective tool for management activities. It can effectively correct the problems and shortcomings in traditional management activities, especially for human resources management. First, in the digital age, the data characteristics of human resources management are more prominent. Data is the important carrier in the life cycle in the process of human resources management, such as performance evaluation, hiring and recruitment, For example, recruitment data, employment data, training data and evaluation data will be entered in the enterprise human resource information system. Second, the management form of human resources organization is flexible. In the digital age, enterprises develop the flexible organization and management form of human resources according to their needs, establish the network and flat organization structure, and give staffs some decision rights. Finally, they should establish a new enterprise incentive mechanism, human resources performance assessment, and the human resources management system consistent with the digital age, so as to improve the effectiveness and comprehensiveness of human resources management evaluation.

\subsection{Challenges of Human Resources Management in the Digital Age}

For human resources management, the advent of the digital age is not only a golden opportunity, but also a difficult challenge, because the advent of the digital age requires relevant enterprises not only to repair the existing paradigm with technical content [3], but also to build a new paradigm from the perspective of information technology. There are high requirements for enterprises. First, it requires the enterprise to have a certain foundation of digital management. All human resource management activities, such as recruitment, employment, training, performance appraisal and other activities, need to adopt digital management. However, most enterprises do not have the appropriate skills, leaders or operation structure to deal with digital management. Second, enterprises need to invest a lot of funds and technologies. In the construction of the information system, whether it is developed by the enterprise itself or relevant human resources software systems are purchased, the cost of its operation and later maintenance is high, and there are high requirements for capital storage and payment capacity of the enterprise. Moreover, the information management platform required by digital technology needs to be operated by people. Even if the information management platform required by digital technology needs person with relevant technology and professional knowledge to operate, but many enterprises lack talents who understand both information technology and human resource management knowledge, which will affect the actual effect of human resource management.

\section{Strategies for Constructing the New Paradigm of Human Resources Management in the Digital Age}

With the rapid development of information technology, the popularity of the 
Internet and the advent of the digital age, the interaction between people will inevitably produce a large amount of data [4]. Many tasks of human resources management can be converted into data. These data imply the needs, emotions and in-depth communication between employees and managers. Everyone in the enterprise will be affected by the logic behind the big data. No enterprise or human resources management can avoid big data or "digital human". In addition, the digital age is also an age in which customer value comes first. Information is becoming more symmetrical and transparent. Customers and employees can interact without boundary and express their value appeals and expectations without obstacles. Here, we summarize the new paradigm of human resources management into the following aspects:

\subsection{Precise Selection of Personnel and Construction of the Information Interaction Platform}

In the past, on-site recruitment, career talk and online resume submission were the traditional methods of personnel recruitment [5]. In the digital age, Human Resources Department can obtain talents accurately through more channels. For example, through mobile phone and special APP, it can update and publish recruitment information at any time on the mobile management platform of the enterprise, large enterprises such as Huawei, Tencent and Country Garden can view their recruitment information by downloading their app clients, job seekers do not need to enter the crowded talent market. They can read recruitment information and submit resumes anytime and anywhere by clicking on their mobile phones. This brings convenience to both parties, and creates conditions for enterprises to accurately recruit suitable talents. The change of recruitment mode not only enables human resource managers of enterprises to easily obtain recruitment information, but also to keep with the times and innovate recruitment work. In the digital age, candidates can search in different ways when submitting their resumes, and understand the enterprise in all directions and in many ways. At the same time, it also means that if enterprises want to attract more candidates they must make good use of the Internet platform. Therefore, we need to change and innovate the traditional recruitment mode and create an information interaction platform with enterprise characteristics.

\subsection{Data Mining and Establishment of the Appeal Platform}

Human resources management is based on data and speaks and makes decisions with data. In the digital age, the huge data accumulated by the interconnection between people and organizations and between people provides endless scientific basis for the procedural and non-procedural decision-making of human resources. Enterprises need to collect data about the worksite, employees and employees' interaction and interconnection anytime and anywhere, digitalize employees' emotions, understand employees' value data and expectations through big data analysis, improve the scientificity of talent matching decision-making, 
analyze the critical point of labor-management relationship conflict, and attach importance to employees' space of free expression, so that they can appeal for their interests on a reasonable platform. The greater the free space is, the more satisfied their interest appeal can be. It can eliminate the negative emotions of employees, improve their ability of self-driving and self-management, and allow them to make progress with enterprises for mutual benefit and win-win result. Therefore, Human Resources Management Department of enterprises should actively establish a reasonable and open platform for interest appeal in LAN, so that managers can grasp employees' ideas in time, deeply grasp human nature, discover human emotions and interest appeal from cold data, deduce the general trend from small samples, and provide basis for personnel decision-making. Therefore, Human Resources Management Department needs to establish a fair, open and transparent benefit sharing system, which can enable employees to correct the current distorted concept of benefit sharing, motivate employees, and make employees have more sense of belonging and fairness and work more actively.

\subsection{Knowing How to Judge People and Use Them and Establishment of the Talent Sharing Platform}

Talent database is an indispensable part of the upgrading process of human resources management. In order not to be abandoned by the digital age, industry managers should adapt to the challenges posed by human resources, and fully realize that improving human resources management is based on the advanced information technology platform. Only with effective and extensive information, enterprises can fully establish the human resources management platform for information sharing, fully understand needs and changes of employees from the big data management, know how to judge people and use them, make the best use of people, and actively mobilize the creativity and enthusiasm of staffs. Through the database management, the comprehensive information of staffs is integrated, so that enterprises can adjust their positions or select talents at any time, and input the talent data required by external companies into the company's information database. It is good for the targeted recruitment of talents at any time, and can inject fresh blood into the company. However, the above database can only be established in one way. Employees cannot update the contents stored in the database by them in time, and the information update is not timely, which limits the development of human resources to a certain extent.

\subsection{Establishment of the Value Creation Platform with Cross-Border Thinking}

Human resources management should cross the border, be refined, and construct the value creation network of human resources. Specifically, in the upward direction, human resources management should be connected with the whole business system and strategy of the enterprise; in the downward direction, it should pay attention to the needs of employees; in the inward direction, it should 
be more specialized, refined and unique; in the outward direction, it should cross the traditional border and exchange with external organizations and society; and to the left and right, it should support business more effectively and play the role of a good partner. Therefore, it is necessary for enterprises to build a cross-border human resources integration framework. At this time, a lot of daily work can be done by human resource outsourcing, and the multi-element "cross-border" employment and talent co-management mode can also be adopted. On this basis, the human resources management system should also be reconstructed, enterprise cost should be reduced, the value creation platform of human resources should be created, and the stickiness and loyalty of value creation should be improved, so as to meet the needs of cross-border management.

\section{Conclusion}

In the digital age, challenges and opportunities coexist, and the core of changes in human resources is human changes. Human needs are diversified and individualized, the flowing frequency of people increases, people's loyalty to the organization reduces, and people's value creation ability increases. This change requires the organization to re-examine human, the most important and core resource; truly reconstruct the new paradigm of human resources management from the perspective of human capital; keep pace with the times through the construction of platforms such as information interaction, interest appeal, talent sharing and value creation; add elements of the times while inheriting the excellent traditional human resources management model; make the development of enterprises meet the requirements of the development of the digital age; inject new vitality into the development of enterprises; constantly innovate the human resources management paradigm of enterprises; meet the demands of enterprise development and talent development; promote the innovative development of enterprises; and conform to the trend of development in the digital age. Because I have no real practical experience and limited ability of the enterprise, the analysis of the new paradigm of human resource management only stays at the level of theoretical research, which should be more in-depth analysis, and establish a more refined and operational ability system and sharing information platform, which is worthy of discussion in the follow-up research.

\section{Conflicts of Interest}

The authors declare no conflicts of interest regarding the publication of this paper.

\section{References}

[1] Xu, D.Y., Wang, Y.M. and Wan, W.Q. (2016) Changes in the Brand Management Paradigm in the Digital Age. Western Forum, 5, 9-11.

[2] Drucker, P. (2018) Challenges of Management in the $21^{\text {st }}$ Century. Translated by Zhu, Y.B. China Machine Press, Beijing, 52-54. 
[3] Chen, C.H. (2016) A New Paradigm of Management Is Required in the Sharing Age. Journal of Management, 2, 157-159.

[4] Peng, J.F. (2014) New Thinking of Human Resources Management in the Internet Age. Human Resources Development in China, 8, 6-9.

[5] Lu, S.K. (2019) Study on the Innovation of Human Resources Management of Enterprises in the Digital Economy Age. Enterprise Reform and Management, 1, 89-90. 